\title{
Federalismo Fiscal, Equalização de Renda Institucional e a Política Nacional de Desenvolvimento Regional (PNDR): Uma Análise com Dados em Painel
}

\section{Fiscal Federalism, Institutional Income Equalization and the National Policy for Regional Development (PNDR): An Analysis with Panel Data}

\author{
Claudio Cesar Paiva* \\ Gislaine de Miranda Quaglio** \\ Gleison Lopes Fonseca***
}

\begin{abstract}
Resumo: O artigo propõe uma reflexão sobre a complexidade que envolve a má distribuição de renda institucional no Brasil, através da análise dos desequilíbrios da renda institucional e da gestão fiscal dos entes subnacionais. A disparidade inter e intrarregional de renda é elevada e os mecanismos de equalização são pouco efetivos para equacionar o vertical gap e o horizontal gap, o que mostra a necessidade de aperfeiçoamento permanente das instituições responsáveis pelas relações e políticas federativas. A ideia é de que a visão de planejamento territorial adotada pela Política Nacional de Desenvolvimento regional (PNDR) para reduzir os desequilíbrios regionais deveria considerar o enfrentamento dos hiatos e das fragilidades fiscais dos entes federativos. Os resultados encontrados podem indicar uma possível existência de heterogeneidade entre os grupos, porém, o foco das análises seguiu para a constatação de uma heterogeneidade interna a cada grupo. Neste sentido, o trabalho permitiu, sobretudo, evidenciar os problemas e as precariedades do sistema fiscal brasileiro e das políticas fiscais municipais, podendo subsidiar uma agenda de propostas ligadas às políticas, como a PNDR, de mudanças legislativas e institucionais na temática regional.
\end{abstract}

Palavras-chave: Federalismo fiscal. Equalização fiscal. PNDR.

Abstract: The paper proposes a reflection on the complexity involving the misallocation of institutional income in Brazil, through the analysis of imbalances of institutional income and fiscal management of subnational entities. The inter and intra-regional income disparity is high and equalization mechanisms are ineffective to equate the vertical gap and the horizontal gap, which shows the need for continuous improvement of the institutions responsible for relations and federal policies. The idea is that the vision of territorial planning ad opted by the National Policy for Regional

\footnotetext{
* $\quad$ Doutor em Economia Aplicada pela Universidade Estadual de Campinas (Unicamp). E-mail: claudiopaiva@fclar.unesp.br

* Doutoranda em Economia Aplicada pela Faculdade de Economia, Administração e Contabilidade de Ribeirão Preto da Universidade de São Paulo (USP). Professora de Economia na Universidade de Ribeirão Preto (Unaerp). E-mail: gislaine.dmq@gmail.com

*** Mestre em Administração de Organizações pela Faculdade de Economia, Administração e Contabilidade de Ribeirão Preto da Universidade de São Paulo (USP). Pesquisador do Instituto de Ensino e Pesquisa em Administração (Inepad). E-mail: gleisonlf@gmail.com
} 
Development (PNDR) to reduce regional disparities should consider addressing the gap sand weaknesses of fiscal federal entities. The results found may indicate a situation of heterogeneity between the groups, however, the focus of analysis followed for a finding of internal heterogeneity in each group. In this sense, the research allowed, above all, to highlight problems such as the precariousness of the Brazilian tax system and municipal fiscal policies, and can subsidize an agenda of policy-related proposals, such as a PNDR, of legislative and institutional changes in the regional theme.

Keywords: Fiscal Federalism. Fiscal equalization. PNDR.

JEL Classification: R10; R50; H72; H77.

\section{Introdução}

O problema crônico da má distribuição da renda no país envolve não apenas a renda pessoal como também a renda institucional. A disparidade inter e intrarregional de renda é elevada e os mecanismos de equalização são pouco efetivos e estão longe de alcançar um estágio satisfatório (LOPREATO, PAIVA, 2002 p. 14).

$\mathrm{O}$ arranjo fiscal-federativo brasileiro tem se mostrado insuficiente e, em muitos casos, um entrave para a superação do subdesenvolvimento das estruturas socioeconômicas vigentes em regiões pobres do país. Isso indica que os mecanismos e as instituições, criadas sob o amparo do arranjo federativo gestado na Constituição Federal de 1988, não são suficientes para equacionar o vertical gap, decorrente da relativa concentração de recursos no Governo Central e de encargos nos entes subnacionais, nem o horizontal gap, que conduziria à equidade entre jurisdições de um mesmo nível federativo.

A esta situação se acrescenta o fato de que a ausência de políticas de desenvolvimento regional tem contribuído, sobretudo nos anos de 1990, para o acirramento de um padrão de federalismo competitivo e predatório entre os entes subnacionais, afastando-se das diretrizes propostas na Constituição de 1988, que propunha um padrão de federalismo cooperativo e coordenado.

Nesse contexto, a Política Nacional de Desenvolvimento Regional (PNDR), formulada no início do primeiro Governo Lula, se constituiu como uma sinalização para um rearranjo federativo mais harmonioso e equilibrado, com a criação de novos mecanismos de articulação federativa voltados para concorrer para a redução das desigualdades sociais e regionais.

A proposta do artigo é perscrutar os desequilíbrios da renda institucional e da gestão fiscal dos entes subnacionais, assumindo, desde logo, que os mecanismos clássicos de checks and balances foram incapazes de harmonizar os desequilíbrios federativos e que a visão de planejamento territorial adotada pela PNDR para reduzir os desequilíbrios regionais deveria considerar o enfrentamento dos hiatos e das fragilidades fiscais dos entes federativos. 
Para tanto, essa pesquisa, de caráter exploratório, irá tratar de duas problemáticas correlacionadas. O primeiro aspecto concerne a uma investigação sobre a existência de desequilíbrios na renda institucional nos territórios homogêneos, identificados nos eixos estruturantes das ações e nas múltiplas escalas desenvolvidas para a operacionalização da PNDR. O segundo refere-se à compreensão das disparidades fiscais-financeiras que fragilizam as ações propostas e, consequentemente, os possíveis resultados da política de redução das desigualdades no Brasil.

Para alcançar os objetivos propostos o artigo foi sistematizado em duas grandes partes, além desta introdução e das considerações finais. Na primeira parte, propõe-se discutir brevemente o referencial teórico, particularmente as questões atinentes ao federalismo fiscal, a equalização de renda e a questão regional brasileira. Na segunda parte, apresenta-se a metodologia e discutem-se os resultados, a partir da análise dos dados em painel, de modo a verificar a heterogeneidade ou homogeneidade na renda institucional e as fragilidades fiscais dos grupos de municípios, segundo a tipologia da PNDR, no período de 2006 a 2012.

\section{Revisão Bibliográfica}

A revisão da literatura é composta, primeiro, por uma contextualização do chamado federalismo fiscal, suas principais características e especificidades no caso brasileiro. Nesta seção, destaca-se também a relação entre o pacto federativo e a redução das disparidades de renda institucional. Apresentam-se o debate recente sobre a questão regional brasileira e a concepção da Política Nacional de Desenvolvimento Regional (PNDR).

\subsection{O Federalismo Fiscal e a Equalização de Renda}

O arranjo institucional do federalismo brasileiro, desenhado originalmente por atores e interesses mesmo antes da Proclamação da República (CAVALCANTI, 1900), tem sido marcado por uma trajetória de tensões, constrangimentos e progressos para alcançar o equilíbrio federativo. Em decorrência disso, o sistema federativo tem se caracterizado por um movimento pendular em que ora prevalece um modelo de Estado centralizado, ora um modelo de Estado descentralizado, com maior autonomia dos entes subnacionais.

A despeito da profusão de estudos científicos que procuram apreciar esses movimentos, é forçoso notar que sua compreensão não tem sido algo trivial, nem tampouco questão pacificada, como apontaram Aguirre e Moraes (1997, p. 122), ao proclamar que as discussões atinentes aos conflitos federativos no Brasil têm se caracterizado pela ausência de embasamento teórico adaptado à sua especificidade. 
Entrevê-se, a partir das afirmações de Aguirre e Moraes (1997), que as análises dos arranjos prevalecentes e dos conflitos federativos têm se mostrado no plano conceitual como excessivamente reducionistas, focalizadas, em certos momentos, na dificuldade de enquadramento aos preceitos teóricos do mainstream do federalismo, com suas hipóteses de comportamento maximizador, autointeresse e política como troca ${ }^{1} \mathrm{e}$, em outros, na hipótese de "inversão conceitual" 2 em relação à "matriz" de nosso federalismo (TORRES, 1961; DALLARI, 1986; AFFONSO, 1994).

Nessa perspectiva, é relevante ressaltar que o dissenso, os conflitos e os constrangimentos ao pacto federativo, este entendido como uma forma de organização territorial do poder e de articulação entre o governo central e os governos subnacionais, não necessariamente representam uma frouxidão dos laços que une a Federação, mas a busca por um equilíbrio federativo através de consensos contingentes materializados nas diversas alianças federativas. Isso é perfeitamente compreensível num país de dimensões continentais, que se tornou crescentemente complexo a partir da segunda metade do século XX, porém que ainda convive com uma herança colonial persistente de desigualdades sociais e regionais.

Na prática, as desafiadoras e complexas questões federativas nacionais têm se reduzido ao debate sobre federalismo fiscal, porém sempre tencionado pela necessidade de um reequilíbrio do pacto federativo, que reduza os hiatos fiscais e amplie a capacidade de provisão de bens públicos pelos entes com maiores disparidades sociais.

A relação intrínseca e consagrada entre território e a conformação de arranjos federativos adquire contornos concretos na análise das finanças públicas, particularmente na avaliação da capacidade fiscal das jurisdições. O fato de alguns municípios serem mais ricos que outros possibilita que esses gastem mais com o mesmo nível de esforço fiscal (BIRD; VAILLANCOURT, 2006). As disparidades fiscais-financeiras sinalizam as dificuldades ou a impossibilidade de determinados entes subnacionais participarem ativamente, com aporte de recursos financeiros, de ações públicas cooperadas e compartilhadas.

O reduzido grau de autonomia financeira de alguns entes subnacionais torna-se ainda mais grave quando sobejamente se observa entre os municípios identificados como pobres e de baixo dinamismo econômico, nos termos da tipologia adotada pela PNDR, a existência de elevadas diferenças na estrutura fiscal-financeira. Note-se, no plano fático, que haveria assim significativa heterogeneidade

$1 \quad$ Ver Buchanan e Tullock (1962).

2 Segundo Affonso (1994, p. 57), a "inversão conceitual possui raízes históricas muito definidas. Em primeiro lugar, ao contrário da constituição da clássica Federação americana, em que as colônias, e posteriormente os estados, se uniram para criar um Estado federal, no Brasil o Governo central precedeu as esferas subnacionais". 
fiscal-financeira no grupo de municípios caracterizados por certa concentração de pobreza.

Dessa forma, torna-se imprescindível a intervenção do Estado, no sentido de reduzir as disparidades na renda institucional, através da promoção da equalização da capacidade de gasto. Essa intervenção deve ser conduzida pelo esforço para equacionar o "vertical gap", decorrente do descompasso na aplicação normativa do federalismo fiscal, que promove relativa concentração de recursos fiscais e financeiros no Governo Central e de encargos nos entes subnacionais, e o horizontal gap, que conduziria à equidade entre jurisdições de um mesmo nível federativo (BIRD; SMART, 2002; SHAH, 1994).

Ao discutir as diretrizes para a construção de uma nova fórmula para as transferências fiscais intergovernamentais no Brasil, particularmente as associadas ao Fundo de Participação dos Estados (FPE), Ter-Minassian (2012) realiza os seguintes apontamentos:

[...] dado que as receitas próprias dos GSN [Governos Subnacionais] normalmente estão muito aquém dos montantes necessários para a execução dos gastos que estão sob sua responsabilidade com um nível razoável de eficiência, as transferências intergovernamentais são utilizadas em todos os países para cobrir as brechas verticais resultantes. As transferências intergovernamentais também são utilizadas para perseguir um conjunto de outros objetivos, incluindo a redistribuição regional dos recursos, a compensação por externalidades interjurisdicionais e a execução das prioridades dos governos do nível mais alto em áreas administradas pelos governos de nível mais baixo. A importância relativa associada a estes objetivos em cada país contribui substancialmente, junto com várias restrições econômicas e institucionais, a definir a natureza e a combinação das transferências intergovernamentais dos países. (TER-MINASSIAN, 2012, p. 08, grifo do autor).

As transferências fiscais intergovernamentais têm sido objeto de acaloradas controvérsias na área de finanças públicas a despeito de noções de justiça e equidade serem frequentemente utilizadas como argumentação para justificar tal necessidade.

A literatura econômica do federalismo fiscal tem se concentrado na análise das dificuldades de operacionalização de uma política de equalização, particularmente nas divergências e inadequações existentes entre os sistemas de transferências fiscais intergovernamentais e a teoria normativa da descentralização fiscal. Os principais conflitos teóricos têm sido a influência do componente político sobre os critérios técnicos de alocação e a própria complexidade para se definir os referidos critérios, dadas as dificuldades técnicas para o cálculo da arrecadação potencial de cada jurisdição, avaliação da qualidade do gasto, análise do custo-benefício e das preferências por bens e serviços, o hiato fiscal, etc (DOWNES; POGUE, 1992; SHAH, 1994; AHMAD; CRAIG, 1997; TER-MINASSIAN, 1997). 
$\mathrm{Na}$ tentativa de contribuir para a sistematização dos mecanismos de equalização de renda, Bird e Smart (2002) sugerem a seguinte distinção:

Equalization transfers may have two distinct rationales. The first is to provide the necessary underpinning for decentralization in general, by equalizing to some level the fiscal capacity of territorial entities, thus putting all closer to being on the same footing with respect to incentives. A second rationale might be to provide sufficient resources to enable all local governments, even the smallest and poorest, to provide a basic package of local services. From a purely economic point of view, the second of these objectives may appear to make little sense. (BIRD; SMART, 2002, p. 902-903)

Diante do exposto nesta revisão, tornou-se possível depreender que, para se atingir o objetivo de equalização horizontal da renda institucional, é necessária a ampliação dos mecanismos de transferências verticais, de caráter eminentemente redistributivo, o que implica: a) a definição de um montante de recursos orçamentários do Governo Federal, de caráter não devolutivo e transitório, que atenda exclusivamente a critérios de equidade; b) o estabelecimento de condicionalidades para o acesso aos recursos, como, por exemplo, exercício pleno da competência tributária e c) a coordenação federativa, de modo a estabelecer metas e padrões mínimos dos bens e serviços públicos a serem ofertados.

A propósito, é necessário notar que os pressupostos apresentados anteriormente procuram assimilar os pontos exitosos de diversos sistemas fiscais-federativos. Em muitos países o foco na equalização fiscal se restringe à promoção da equalização da capacidade de gasto por meio de transferências intergovernamentais, sobretudo através de transferências voluntárias promovidas pelo Governo Central.

Ao estabelecer condicionantes tanto para acesso quanto para o uso dos recursos, procura-se, por um lado, coibir a negligência tributária e a "preguiça fiscal”, ou seja, decisões de natureza política que limitam o exercício do potencial tributário do ente federativo e, por outro, revelar a visão estratégica do Governo Federal, com a definição de um conjunto de escolhas estratégicas materializadas em planos, prioridades e metas a serem alcançadas, além da preocupação com o padrão de provisão de bens públicos (ARRETCHE et al., 2007).

Adicionalmente, o estabelecimento de mecanismos para a equalização da renda institucional, através de recursos condicionados, também procura minimizar as ações discricionárias dos entes subnacionais e mitigar efeitos indesejáveis vinculados aos processos de transferências intergovernamentais, como o flypaper effect e o efeito captura de recursos por governantes e burocratas (MENDES, 2004, 2005; INMAN, 2008). ${ }^{3}$

3 O chamado efeito flypaper representa um fenômeno encontrado na literatura empírica no qual os gastos dos governos locais têm sensibilidade maior a aumentos nas transferências recebidas de 
Ainda assim, pode-se inferir ceteris paribus que o critério da condicionalidade não apresenta efeitos danosos à autonomia dos entes subnacionais, ao passo que tende a realçar o papel de coordenação do Governo Federal, conforme consagrado na literatura normativa e positiva do federalismo fiscal.

No caso brasileiro nota-se, ainda, que as tensões federativas estão se ampliando em decorrência das baixas taxas de crescimento econômico do país e da forte centralização de recursos fiscais no Governo Federal. Com efeito, torna-se premente a implementação de uma reforma do sistema de relações fiscais intergovernamentais que tenha como meta a equalização da renda institucional dos agrupamentos de municípios que compõem cada mesorregião diferenciada, identificadas pela PNDR, como forma de equilibrar a capacidade dos diferentes governos subnacionais de proverem adequadamente bens e serviços sob a sua responsabilidade.

A manutenção das disparidades na capacidade fiscal dos entes subnacionais tem implicações negativas para a efetividade das políticas públicas, o que permite estabelecer, grosso modo, a mesma correlação na implementação das políticas regionais propostas no âmbito da PNDR, ou seja, não deverão lograr êxito se não forem enfrentadas as diferenças fiscais-financeiras, que impõem, dentre outras limitações, uma exígua capacidade de governança e de cooperação.

\subsection{A Questão Regional Brasileira e a Política Nacional de Desenvolvimento Regional (PNDR)}

Na posição de uma economia em desenvolvimento e detentora de dimensões continentais, o Brasil se caracterizou por uma complexa trajetória no que tange aos processos de integração físico-territorial e de integração econômica. Os desdobramentos de tais processos acabaram por conduzir a grandes desequilíbrios e desigualdades entre as regiões.

A despeito da dinâmica regional se apresentar historicamente por meio de "ilhas regionais", condicionadas pelo desempenho dos mercados externos (OLIVEIRA, 1993), a problemática regional no país se manifesta explicitamente somente a partir do século XX (BACELAR, 2000), quando o Brasil é forçado a redirecionar seu eixo de acumulação de uma economia primário-exportadora para uma economia industrial, o que refletiu numa nova divisão do trabalho entre as regiões do país.

outras esferas de governo do que a aumentos nas rendas obtidas localmente. Já o efeito captura está relacionado a interesses corporativistas e/ou partidários, ou seja, de segmentos e interesses específicos. 
Uma vez que o mercado interno é a variável que comanda a atividade produtiva, deu-se o primeiro sinal de integração nacional, com surgimento da articulação comercial e produtiva inter-regional (GUIMARÃES NETO, 1997a).

Inicialmente, na integração comercial, a produção ocorria no centro dominante, a região Centro-Sul, e as mercadorias eram distribuídas para as demais regiões consideradas periféricas, principalmente a região Nordeste. O centro dominante conduzia a seu ritmo os efeitos de estímulo às regiões periféricas. Num segundo momento, ocorreu a intensificação da dinâmica econômica e as relações evoluíram para uma articulação produtiva. Na articulação produtiva a supremacia da indústria paulista em termos de produtividade e eficácia foram fatores de grande vantagem competitiva em relação às indústrias das demais regiões. Dessa forma, os impactos da competição inter-regional para regiões como o Norte e Nordeste foram negativos, pois estas regiões não lograram acompanhar a mudança do capital mercantil para o produtivo que, conforme Cano (2007, p. 259), seria "a questão básica do atraso periférico".

Naquele momento, a questão regional brasileira surge predominantemente pelas relações regionais articuladas que, na medida de sua construção, determinaram diferenciações importantes entre as regiões do país, de acordo com a participação na nova divisão do trabalho.

Além dos fatores relacionados à concorrência inter-regional, a grande seca e as precárias condições sociais pelas quais passava a região Nordeste, nos anos de 1950, foram fatores-chave para a intensificação dos debates sobre os problemas regionais no Brasil. O agravamento do quadro social e econômico das regiões periféricas foi decisivo para a implementação de algumas ações com foco na "região problema" do país. Exemplos que remetem à "Operação Nordeste", com a constituição do Grupo de Trabalho para o Desenvolvimento do Nordeste (GTDN) e da criação da Superintendência do Desenvolvimento do Nordeste (Sudene) (FURTADO, 2009) até a redefinição das estratégias de desenvolvimento regional brasileiro e sua incorporação aos Planos Nacionais de Desenvolvimento (I e II PNDs) (CARVALHO, 2008).

O debate em torno dos problemas das regiões Norte e Nordeste resultou na constatação de uma atuação necessária do Estado, no sentido de promover uma nova configuração regional no Brasil. Neste caso, a capacidade do Estado de influenciar e dinamizar a atividade produtiva nas regiões menos desenvolvidas ocorreu, sobretudo, mediante incentivos fiscais e financeiros instituídos a partir da década de 1950.

Políticas tipificadas como top-down, implementadas por meio de incentivos fiscais e financeiros, como o Sistema 34/18, os fundos de investimentos do Nordeste e da Amazônia (FINOR e FINAM), a criação de instituições como o Banco do Nordeste Brasileiro (BNB) e o Banco da Amazônia (BASA) se mostraram relevan- 
tes para a ocorrência de um movimento de desconcentração da atividade produtiva identificada a partir da década de 1970 (AZZONI, 1986; GUIMARÃES NETO, 1986,1989, 1997a; DINIZ, 1993; CANO, 1997, 2008).

O processo de desconcentração ocorreu com a ação ativa do Estado, por meio do provimento de infraestrutura, de incentivos fiscais e financeiros e de articulação dos capitais envolvidos. Contudo, no momento em que o Estado deixou de atuar ativamente, tal processo, antes virtuoso e convergente, não se sustentou. Diante da crise fiscal e financeira do Estado, da aceleração inflacionária e do quadro econômico deteriorado, a partir de meados da década de 1980, o Estado perdeu sua capacidade de manter qualquer programa ou incentivo que fossem diferentes da estabilização econômica e da recuperação dos fundamentos macroeconômicos do país.

Adicionalmente, concepções teórico-econômicas acerca do novo papel do Estado, principalmente o receituário que propunha a redução de sua atuação na economia e a adesão às aberturas comercial e financeira, colaboraram para que as estratégias e o planejamento regional fossem abandonados (BRANDÃO, 2004; MONTEIRO NETO, 2005).

O período a partir de meados da década de 1980, portanto, é caracterizado como de ruptura do processo de desconcentração produtiva no Brasil. Dentre as várias concepções teóricas que buscaram definir a nova questão regional brasileira, destacam-se a ideia de reconcentração produtiva (DINIZ, 1993), de esgotamento do processo de desconcentração (GUIMARÃES NETO, 1997b), de uma nova dinâmica regional caracterizada pela fragmentação nacional (PACHECO, 1996a; 1996b; 1998) e de um padrão diferenciado de desconcentração conduzido pelo ambiente neoliberal (CANO, 2011).

A compatibilidade de reconcentração com fragmentação demonstrou que a questão regional no país não se caracteriza mais pelas desigualdades macrorregionais ou mesmo apenas pelas "regiões problema". Nesse novo contexto, o debate caminhou para a percepção de que desníveis na escala macrorregional coexistem com desníveis intrarregionais. Ações pontuais e desarticuladas deveriam ser substituídas por planejamento estruturado em diretrizes e princípios implementados na escala sub-regionalizada.

Ao contrário do abandono que ocorreu na esfera política, a preocupação com o desenvolvimento regional continuou presente nas discussões do meio acadêmico. Diante da persistência e das novas características das desigualdades regionais no país, alguns estudiosos do desenvolvimento regional brasileiro intensificaram discussões e fomentaram a retomada de uma política regional na agenda governamental. Tal retomada se deu a partir da proposta para uma Política Nacional de Desenvolvimento Regional (PNDR) (BRASIL, 2003), institucionalizada em 2007. 
A PNDR se diferencia por considerar no seu escopo de atuação tanto as profundas desigualdades de níveis de vida e de oportunidades quanto os diferentes potenciais de desenvolvimento das sub-regiões brasileiras. Caracteriza-se, assim, por ser uma política voltada para a redução das desigualdades e, por conseguinte, promover o desenvolvimento regional mediante incentivo às atividades produtivas locais. A diferenciação interna de cada sub-região é tratada como potencialidade e vista como ponto central de confluência entre os interesses nacionais de crescimento e desenvolvimento econômico e de inserção competitiva global.

Para alcançar tais objetivos a PNDR adotou uma tipologia no sentido de diferenciar as regiões brasileiras. Tal diferenciação mostrou-se importante para que as ações fossem direcionadas de modo a atender as necessidades específicas de cada localidade. A partir do cruzamento entre as variáveis rendimento domiciliar médio por habitante e variação dos PIBs municipais, surgiu a tipologia sub-regional: alta renda, dinâmica, estagnada e baixa renda (GALVÃO; VASCONCELOS, 1999; BRASIL, 2003). Nas sub-regiões denominadas alta renda, o alto rendimento domiciliar é verificado independentemente do dinamismo. Ao contrário, nas sub-regiões dinâmicas, o rendimento é médio ou baixo, porém apresenta alto dinamismo. Já nas sub-regiões estagnadas, o rendimento domiciliar é médio e o dinamismo econômico pode ser médio ou baixo. Por fim, nas sub-regiões de baixa renda tanto o rendimento domiciliar quanto o dinamismo são baixos.

As ações da PNDR possuem foco, sobretudo, nas regiões estagnadas, com baixa renda e dinamismo recente. As formas e instrumentos de financiamento variam desde recursos do Orçamento Geral da União e dos entes federativos, Fundos Constitucionais de Financiamento, Fundos de Desenvolvimento Regional e incentivos fiscais e financeiros de agentes oficiais, como os Bancos de Desenvolvimento.

Mesmo após a institucionalização da PNDR alguns obstáculos não foram superados, o que tem limitado a eficiência da política. A precária articulação da governança institucional, a sobreposição de áreas e competências, a necessidade de recursos e a importância de utilizar a tipologia como um instrumento de ação demonstrou que a questão regional no Brasil ainda precisa ser foco efetivo das ações de governos e da sociedade. Temas como a governança, participação social, diálogo federativo, financiamento, critérios de elegibilidade estão abertos para que condições de viabilidade e aplicabilidade da política sejam construídas e, assim, as desigualdades sociais e econômicas no país comecem a ser dirimidas (BRASIL, 2012).

Dentre todos esses obstáculos uma temática constantemente negligenciada é a da desigualdade de renda institucional, que resulta em capacidades diferenciadas de responder adequadamente à demanda da comunidade local. 
O critério de separação dos grupos para a análise segue a tipologia proposta pela PNDR. Para tornar a classificação territorial mais específica por município, adotou-se uma derivada da tipologia que considera a divisão da faixa de média renda da PNDR em duas: a média renda inferior e a média renda superior. Tal metodologia foi elaborada pelo Banco Nacional de Desenvolvimento Econômico e Social (BNDES) no âmbito de sua Política de Dinamização Regional (PDR), pois, no caso original, a tipologia considera microrregiões e não municípios e, como tal política do Banco dispõe de condições diferenciadas para empreendimentos localizados em municípios de classificação prioritária, a adaptação foi necessária. ${ }^{4} \mathrm{~A}$ partir dessa subdivisão, e tendo em vista as variáveis cruzadas, renda e dinamismo, as observações são agrupadas conforme a Figura 1. O nível de renda domiciliar per capita é composto pela baixa renda no primeiro quartil, as médias rendas no segundo e terceiro quartil e alta renda no quarto quartil. Da mesma forma foi adotada a distribuição em quartis na variação do PIB.

Figura 1 - Classificação bidimensional dos municípios

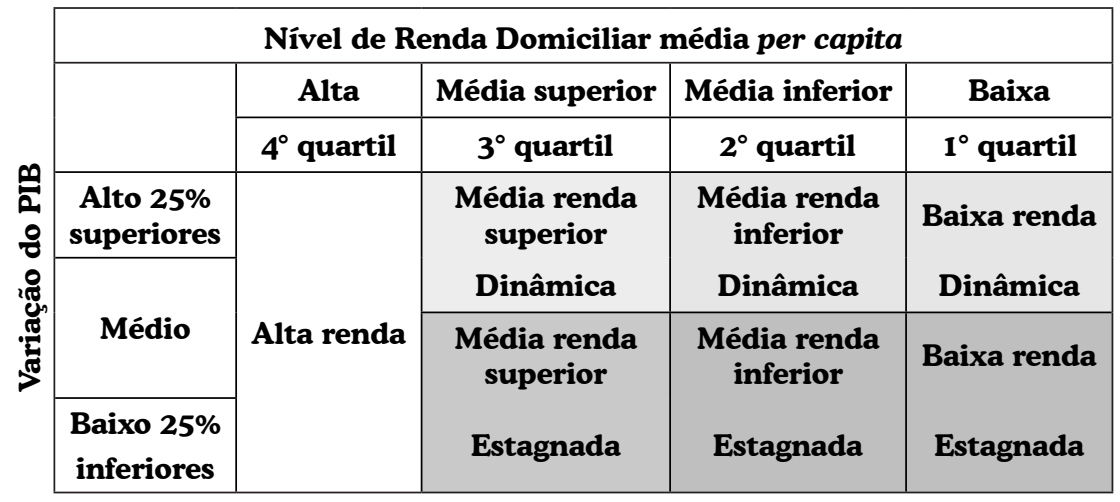

Fonte: Elaboração própria com base no Banco Nacional de Desenvolvimento Econômico e Social (2016).

Os dados para as estimativas são de 4.036 municípios brasileiros entre os anos de 2006 a 2012 e foram obtidos na Secretaria do Tesouro Nacional (STN), por meio do relatório de Finanças do Brasil (FINBRA), publicado anualmente com os dados contábeis dos municípios. Como variável dependente da análise foi utilizado o resultado da execução orçamentária. A relação de todas as variáveis dependente e independentes, suas contas componentes e fonte de extração dos dados, são apresentados no Quadro 1.

4 Para mais informações, acessar a página da PDR: http://www.bndes.gov.br/wps/portal/site/home/onde-atuamos/desenvolvimento-regional-territorial/politica-de-dinamizacao-regional-pdr. 
A escolha do resultado da execução orçamentária como variável dependente do estudo visou atender ao problema de pesquisa em análise, indicando as variáveis que influenciam o comportamento de superávit ou déficit orçamentário nos municípios, considerando-se como um comportamento positivo das finanças municipais para a obtenção de superávit e o inverso para a obtenção de déficits (SANTOLIN; JAYME JUNIOR; REIS, 2009; ZUCCOLOTTO; RIBEIRO; ABRANTES, 2009).

Quadro 1 - Variáveis do estudo

\begin{tabular}{|c|c|c|c|}
\hline Variável & $\begin{array}{l}\text { Função na } \\
\text { análise }\end{array}$ & Composição & Fonte \\
\hline Sup_Def & Dependente & $\begin{array}{c}\text { Receita Orçamentária menos } \\
\text { a Despesa Orçamentária }\end{array}$ & $\begin{array}{c}\text { Balanço Orçamen- } \\
\text { tário (Receitas e } \\
\text { Despesas) }\end{array}$ \\
\hline Rec_Trib & Independente & Receita Tributária & $\begin{array}{l}\text { Balanço Orçamen- } \\
\text { tário (Receitas) }\end{array}$ \\
\hline Cota_ICMS & Independente & Cota parte do ICMS & $\begin{array}{l}\text { Balanço Orçamen- } \\
\text { tário (Receitas) }\end{array}$ \\
\hline Cota_FPM & Independente & $\begin{array}{l}\text { Cota parte do Fundo de Par- } \\
\text { ticipação dos Municípios }\end{array}$ & $\begin{array}{c}\text { Balanço Orçamen- } \\
\text { tário (Receitas) } \\
\end{array}$ \\
\hline Out_Rec_Cor & Independente & Outras Receitas Correntes & $\begin{array}{c}\text { Balanço Orçamen- } \\
\text { tário (Receitas) }\end{array}$ \\
\hline Rec_Cap & Independente & Receitas de Capital & $\begin{array}{l}\text { Balanço Orçamen- } \\
\text { tário (Receitas) }\end{array}$ \\
\hline Desp_Pes & Independente & $\begin{array}{c}\text { Despesas de Pessoal ou Apli- } \\
\text { cações Diretas de Pessoal } \\
\text { e Encargos Sociais menos } \\
\text { Contratação por Tempo } \\
\text { Determinado. }\end{array}$ & $\begin{array}{l}\text { Balanço Orçamen- } \\
\text { tário (Despesas) }\end{array}$ \\
\hline Out_Desp_C & Independente & Outras Despesas Correntes & $\begin{array}{l}\text { Balanço Orçamen- } \\
\text { tário (Despesas) }\end{array}$ \\
\hline Desp_Cap_Ajust & Independente & $\begin{array}{l}\text { Despesas de Capital menos } \\
\text { Amortização da Dívida }\end{array}$ & $\begin{array}{l}\text { Balanço Orçamen- } \\
\text { tário (Despesas) }\end{array}$ \\
\hline Amort_Div & Independente & Amortização da Dívida & $\begin{array}{l}\text { Balanço Orçamen- } \\
\text { tário (Despesas) }\end{array}$ \\
\hline Restos_Pagar & Independente & Restos a Pagar & $\begin{array}{c}\text { Balanço Orçamen- } \\
\text { tário (Despesas) }\end{array}$ \\
\hline
\end{tabular}

Fonte: Elaboração própria.

Nesse sentido, a escolha das variáveis dependente e independentes se baseou em estudos anteriores sobre o tema (MATIAS; CAMPELLO, 2000; ANDRADE, 2007; MACEDO; CORBARI, 2009; SANTOLIN; JAYME JUNIOR; REIS, 2009; ZUCCOLOTTO; RIBEIRO; ABRANTES, 2009; AZEVEDO, 2013;), optando-se por 
trabalhar com o saldo das contas em valores nominais em detrimento de convertê-las em indicadores, visto o objetivo de avaliar a influência de cada conta na obtenção do superávit ou déficit orçamentário.

Essa adaptação está de acordo com a técnica escolhida para identificar o comportamento do resultado da execução orçamentária (variável dependente) em relação às variáveis explicativas, utilizando-se de um Painel de Dados Balanceado.

Os dados em painel consistem no acompanhamento de uma unidade de corte transversal composta por diversos indivíduos $(\mathrm{N})$, durante o período de períodos (T), caracterizando-se como painel curto - quando N é maior do que $\mathrm{T}$ - ou painel longo - quando $\mathrm{T}$ for maior do que $\mathrm{N}$ (WOOLDRIDGE, 2010).

As vantagens na utilização de dados em painel em detrimento de outras técnicas de análise aplicada, como as séries temporais ou apenas cortes transversais, justifica-se por características tanto do tamanho da unidade de corte, do período de tempo e das características dos sujeitos em estudo, quanto pelo objetivo de verificar se os grupos de municípios divididos pelo critério da PNDR são ou não homogêneos dentro do critério de elegibilidade.

Antes, contudo, cabe esclarecer que o termo homogêneo não é usado neste trabalho seguindo estritamente as definições das divisões regionais do IBGE (1990), mas sim da concepção da PNDR. Refere-se ao espaço definido como sendo invariante com respeito a algum aspecto econômico de interesse. Por exemplo, variáveis como renda e produção, dentre outras do domínio econômico que podem ser utilizadas para a delimitação de espaços ditos homogêneos. As ações da PNDR são direcionadas tanto às chamadas mesorregiões diferenciadas quanto aos chamados espaços sub-regionais (microrregiões homogêneas), conforme segue:

A unidade de articulação das ações federais nas sub-regiões selecionadas é conhecida como "Mesorregião Diferenciada", que se constitui como espaço institucional de formação de consensos. As ações dos programas regionais sob governança do MI são, portanto, preferencialmente implementadas e desenvolvidas em escala mesorregional ou em outros espaços sub-regionais que justifiquem uma ação diferenciada do governo federal, em consonância com o objetivo estabelecido pela PNDR (BRASIL, 2003, p. 15).

Sobre algumas vantagens no uso de dados em painel, Baltagi (2005) explica que: i) determinadas unidades de cortes transversais podem conter heterogeneidade, o que não é controlado pelas técnicas de corte transversal ou séries temporais, podendo resultar em análises enviesadas; ii) ao combinar o estudo de repetidas observações em corte transversal, os dados em painel oferecem mais graus de liberdade, maior variabilidade, menos colinearidade entre as variáveis, além de dados mais informativos para avaliar as dinâmicas das mudanças e iii) são melhores para mensurar efeitos que não seriam detectados em séries temporais 
ou cortes transversais, como os que envolvem o estudo de modelos complexos de comportamento, em que os dados em painel permitem distinguir e acompanhar os efeitos das variáveis sobre os indivíduos.

Corroborando essa ideia, Gujarati e Porter (2011) consideram que os dados em painel devem ser utilizados em detrimento apenas da análise de dados em séries temporais ou em cortes transversais por enriquecerem a análise, apesar de poderem apresentar os problemas inerentes a estas duas formas de análise, heterocedasticidade e autocorrelação, respectivamente, o que pode ser resolvido por uma das técnicas de estimação que serão apresentadas.

De forma simplificada, divide-se e se ajusta o modelo geral de dados em painel em três: i) Modelo Pooled; ii) Modelo de Efeitos Fixos e iii) Modelo de Efeitos Aleatórios. No modelo Pooled se considera que todos os coeficientes de regressão são iguais para todos os indivíduos e que as variáveis independentes são não estocásticas, ou seja, correlacionadas com o termo de erro (WOOLDRIDGE, 2010). Dessa forma, o Modelo Pooled para dados empilhados desconsidera a heterogeneidade (efeito não observável) que possa existir entre os indivíduos e o efeito do tempo e da individualidade entre eles, considerando, portanto, que possuem intercepto comum.

O Modelo de Efeitos Fixos considera essa heterogeneidade, assumindo que as diferenças entre as unidades podem ser capturadas pelas diferenças no intercepto, que representará a diferença de indivíduo para indivíduo. Os interceptos são tratados como um parâmetro desconhecido a ser estimado (GREEN, 2002), captando a heterogeneidade dos indivíduos.

Por fim, o Modelo de Efeitos Aleatórios considera que os valores dos interceptos não sejam constantes, mas sim uma variável aleatória. Assume-se que a amostra foi extraída de uma população maior, com valor médio para o intercepto, em que as diferenças dos indivíduos (heterogeneidade) passam a ser captadas pelo termo de erro e não mais pelos interceptos (WOOLDRIDGE, 2010). Nesse sentido, a constante se torna um parâmetro aleatório não observável.

Para a escolha do modelo mais adequado de estimação de dados em painel, foram aplicados os seguintes testes, procurando testar a consistência dos estimadores: i) Teste F, comparando a regressão do Modelo Pooled com a do Modelo de Efeitos Fixos; ii) Teste de Breusch-Pagan, comparando o Modelo Pooled com o Modelo de Efeitos Aleatórios e iii) Teste de Hausman, comparando o Modelo de Efeitos Fixos com o Modelo de Efeitos Aleatórios (WOOLDRIDGE, 2010).

Na sequência, foram feitas na população as verificações de existência de autocorrelação, pelo teste de Durbin-Watson, e de heterocedasticidade, pelo teste de Wald. Detectada a presença de heterocedasticidade, tornaram-se necessárias algumas adaptações no modelo de estimação, optando-se pela utilização dos Mínimos Quadrados Ponderados (MQP). Os MQP são um caso especial da técnica de 
estimação pelos Mínimos Quadrados Generalizados (MQG), sendo empregados quando se detecta a heterocedasticidade em uma população, já que eles a corrigem, ao minimizarem a soma dos quadrados dos resíduos ponderada, colocando menor peso nas observações com uma variância de erro mais alta (WOOLDRIDGE, 2010).

\section{Análise dos Resultados}

O primeiro aspecto de investigação concerne à existência de desequilíbrios na renda institucional nos territórios homogêneos (mesorregiões desagregadas em municípios), identificados nos eixos estruturantes das ações e nas múltiplas escalas desenvolvidas para a consecução da PNDR. Para tanto, foram realizados os testes dos efeitos, com o propósito de identificar a adequação dos dados analisados aos modelos de efeitos pooled, fixos ou aleatórios.

Conforme dados da Tabela 2, constatou-se que o modelo de efeitos fixos foi predominante, o que permite aduzir a existência de correlação entre os efeitos individuais não-observados de cada município com as variáveis adotadas. Dessa forma, ao verificar que mesmo após agrupar todos os municípios conforme sua classificação e, assim, tornando-os grupos homogêneos, todos os modelos apresentaram efeitos fixos.

Esse fato revela que apesar de já estarem divididos em grupos pela PNDR, possuem heterogeneidade nos dados, o que, no caso da presente pesquisa, indica desequilíbrios no rendimento institucional dentro de cada território homogeneizado. Tal heterogeneidade apresenta-se específica, porém, constante para cada município ao longo do tempo analisado. 
Tabela 2 - Testes dos efeitos: fixos, aleatórios e pooled

\begin{tabular}{c|ccc|ccc|ccc}
\hline \multirow{2}{*}{ Modelo } & \multicolumn{2}{|c}{ Teste F: Fixo x Pooled } & \multicolumn{2}{c}{$\begin{array}{c}\text { Teste Breusch-Pagan: } \\
\text { Aleatório x Pooled }\end{array}$} & \multicolumn{2}{c}{$\begin{array}{c}\text { Teste Hausman: } \\
\text { Aleatório x Fixo }\end{array}$} \\
\cline { 2 - 10 } & $\mathbf{F}$ & p-valor & Efeito & $\mathbf{X}^{\mathbf{2}}$ & p-valor & Efeito & $\mathbf{X}^{\mathbf{2}}$ & p-valor & Efeito \\
\hline \multirow{2}{*}{ Geral } & 10,5579 & 0 & Fixo & 8858,43 & 0 & Aleatório & 14904 & 0 & Fixo \\
1 & 11,3845 & 0 & Fixo & 2675,99 & 0 & Aleatório & 5110,4 & 0 & Fixo \\
2 & 4,3832 & $9,45 E-91$ & Fixo & 184,825 & $4,29 E-42$ & Aleatório & 474,52 & $1,22 E-95$ & Fixo \\
3 & 4,80996 & $3,34 \mathrm{E}-268$ & Fixo & 1008,29 & $2,83 \mathrm{E}-221$ & Aleatório & 1100,7 & $3,67 \mathrm{E}-230$ & Fixo \\
4 & 2,75965 & $3,67 \mathrm{E}-27$ & Fixo & 43,7717 & $3,69 \mathrm{E}-11$ & Aleatório & 229,49 & $1,10 \mathrm{E}-43$ & Fixo \\
5 & 2,7389 & $8,01 \mathrm{E}-85$ & Fixo & 355,726 & $2,40 \mathrm{E}-79$ & Aleatório & 409,87 & $7,48 \mathrm{E}-82$ & Fixo \\
6 & 3,17565 & $4,27 \mathrm{E}-48$ & Fixo & 195,529 & $1,98 \mathrm{E}-44$ & Aleatório & 171,93 & $1,10 \mathrm{E}-31$ & Fixo \\
7 & 5,29304 & $1,89 \mathrm{E}-180$ & Fixo & 374,372 & $2,09 \mathrm{E}-83$ & Aleatório & 1162,8 & $1,53 \mathrm{E}-243$ & Fixo \\
\hline
\end{tabular}

Fonte: Elaboração própria.

O segundo aspecto refere-se à compreensão das disparidades fiscais-financeiras que fragilizam as ações propostas e, por conseguinte, os possíveis resultados da política de redução das desigualdades brasileiras. Para tanto, foram estimados os modelos para cada grupo de municípios previamente definidos.

Nos modelos geral e alta renda, cujos resultados são dispostos na Tabela 3, a maioria das variáveis se mostrou significativa para explicar o comportamento da variável dependente, ou seja, explicar o resultado orçamentário dos municípios, exceto a rubrica amortização da dívida para o grupo de alta renda. Os coeficientes de explicação $\mathrm{R}^{2}$ indicaram uma capacidade de explicação de $42 \%$ no modelo do grupo geral e $44 \%$ no modelo do grupo de alta renda.

As variáveis receitas de capital e despesas de capital ajustada registraram os maiores coeficientes dentre os modelos analisados, sendo que as receitas apresentaram efeito positivo e as despesas efeito negativo. As receitas tributárias registraram efeito positivo, porém, com coeficiente não tão expressivo. Já as despesas de pessoal e as outras despesas correntes, que impactaram negativamente, mantiveram-se na média entre os demais modelos. A rubrica restos a pagar apresentou efeito negativo, porém, com coeficiente baixo para ambos os grupos.

As variáveis indicativas das transferências intergovernamentais também se revelaram importantes no contexto dos grupos de municípios analisados. No caso dos grupos geral e alta renda, a cota parte do ICMS registrou coeficientes maiores do que os coeficientes do FPM, não obstante, ambos apresentaram efeitos positivos no resultado orçamentário. 
Tabela 3 - Resultados do painel de dados para os modelos geral e alta renda

\begin{tabular}{c|ccc|ccc}
\hline \multirow{2}{*}{ Variável } & \multicolumn{3}{|c|}{ Modelo Geral } & \multicolumn{3}{c}{ Modelo 1 } \\
\cline { 2 - 7 } & Coeficiente & p-valor & & Coeficiente & p-valor & \\
\hline Const & -272182 & $<0,00001$ & $* * *$ & -111201 & 0,00005 & $* * *$ \\
Rec_Trib & 0,156515 & $<0,00001$ & $* * *$ & 0,147936 & $<0,00001$ & $* * *$ \\
Cota_ICMS & 0,215501 & $<0,00001$ & $* * *$ & 0,269356 & $<0,00001$ & $* * *$ \\
Cota_FPM & 0,194651 & $<0,00001$ & $* * *$ & 0,240607 & $<0,00001$ & $* * *$ \\
Out_Rec_Cor & 0,452085 & $<0,00001$ & $* * *$ & 0,496542 & $<0,00001$ & $* * *$ \\
Rec_Cap & 0,616159 & $<0,00001$ & $* * *$ & 0,670631 & $<0,00001$ & $* * *$ \\
Desp_Pes & $-0,0261188$ & $<0,00001$ & $* * *$ & $-0,0724132$ & $<0,00001$ & $* * *$ \\
Out_Desp_C & $-0,109148$ & $<0,00001$ & $* * *$ & $-0,10971$ & $<0,00001$ & $* * *$ \\
Desp_Cap_Ajust & $-0,565271$ & $<0,00001$ & $* * *$ & $-0,632979$ & $<0,00001$ & $* * *$ \\
Amort_Div & $-0,171468$ & $<0,00001$ & $* * *$ & 0,00550658 & 0,89206 & \\
Restos_Pagar & $-0,11634$ & $<0,00001$ & $* * *$ & $-0,100746$ & $<0,00001$ & $* * *$ \\
R-quadrado & 0,428465 & & & 0,447771 & & \\
\hline
\end{tabular}

Fonte: Elaboração própria.

Nos modelos de média renda superior dinâmica e estagnada (Tabela 4), a maioria das variáveis se mostrou significativa para explicar o resultado orçamentário, exceto a amortização da dívida para o grupo de média renda dinâmica. No que se refere à capacidade preditiva, registrou-se 39\% no modelo do grupo média renda superior dinâmica e 35\% no modelo do grupo média renda superior estagnada.

As variáveis receitas tributárias, receitas de capital e despesas de capital ajustada também foram destaques nesses dois grupos de municípios, já que todos os coeficientes foram elevados, mantendo efeito positivo das receitas e efeito negativo nas despesas. As despesas de pessoal no grupo média renda superior dinâmica, ao contrário dos demais grupos, impactou positivamente no resultado orçamentário. De qualquer forma, nota-se que o valor p desse indicador foi um dos poucos a considerar significância estatística ao nível de 5\%. Também no grupo de média renda superior a variável restos a pagar apresentou efeito negativo, com coeficiente alto.

Já para o modelo do grupo média renda superior estagnada registrou-se alto impacto negativo das despesas de pessoal e da amortização da dívida. Além disso, é interessante destacar o alto impacto positivo do coeficiente de outras receitas correntes. 
As variáveis relacionadas às transferências intergovernamentais registram o inverso dos grupos analisados anteriormente. No caso dos grupos de média renda superior dinâmica e estagnada, os coeficientes do FPM e cota parte do ICMS mantiveram seus efeitos positivos no resultado orçamentário, entretanto, ocorreu uma inversão nos coeficientes de maior impacto, com o FPM passando a se apresentar maior do que a cota parte do ICMS.

Tabela 4 - Resultados do painel de dados para os modelos de média renda superior dinâmica e estagnada

\begin{tabular}{c|ccc|ccc}
\hline \multirow{2}{*}{ Variável } & \multicolumn{3}{|c|}{ Modelo 2 } & \multicolumn{3}{c}{ Modelo 3} \\
\cline { 2 - 7 } & Coeficiente & p-valor & & Coeficiente & p-valor \\
\hline Const & -150519 & 0,00109 & $* * *$ & -471723 & $<0,00001$ & $* * *$ \\
Rec_Trib & 0,23248 & $<0,00001$ & $* * *$ & 0,320851 & $<0,00001$ & $* * *$ \\
Cota_ICMS & 0,108555 & $<0,00001$ & $* * *$ & 0,218543 & $<0,00001$ & $* * *$ \\
Cota_FPM & 0,145323 & $<0,00001$ & $* * *$ & 0,273176 & $<0,00001$ & $* * *$ \\
Out_Rec_Cor & 0,194225 & 0,00005 & $* * *$ & 0,731761 & $<0,00001$ & $* * *$ \\
Rec_Cap & 0,544657 & $<0,00001$ & $* * *$ & 0,547427 & $<0,00001$ & $* * *$ \\
Desp_Pes & 0,0253463 & 0,01932 & $* *$ & $-0,124169$ & $<0,00001$ & $* * *$ \\
Out_Desp_C & $-0,0912248$ & $<0,00001$ & $* * *$ & $-0,124356$ & $<0,00001$ & $* * *$ \\
Desp_Cap_ & $-0,500986$ & $<0,00001$ & $* * *$ & $-0,419657$ & $<0,00001$ & $* * *$ \\
Ajust & $-0,0465306$ & 0,55611 & & $-0,341651$ & $<0,00001$ & $* * *$ \\
Amort_Div & $-0,217999$ & $<0,00001$ & $* * *$ & $-0,154322$ & $<0,00001$ & $* * *$ \\
Restos_Pagar & $-0,394912$ & & & 0,358413 & & \\
R-quadrado & 0 & & & & & \\
\hline
\end{tabular}

Fonte: Elaboração própria.

Nos modelos de média renda inferior dinâmica e estagnada (Tabela 5), todas as variáveis, sem exceção, se mostraram significativas para explicar o déficit ou superávit dos municípios. A predição no modelo do grupo Média Renda Inferior Dinâmica foi de $44 \%$ e no modelo do grupo média renda inferior estagnada foi de $25 \%$.

As variáveis receitas de capital e despesas de capital ajustada continuaram a ser destaques também nesses dois grupos de municípios, uma vez que ambos os coeficientes foram elevados, positivos para as receitas e negativos para as despesas. De qualquer forma, constata-se que o grupo de média renda inferior estagnada registrou um dos menores coeficientes para as variáveis supracitadas. No caso das receitas tributárias, o coeficiente se mostrou mais relevante nos municípios dinâmicos. Já as variáveis relacionadas ao endividamento, amortização da dívida 
e restos a pagar, registraram elevados coeficientes negativos em comparação com os demais grupos.

No caso das variáveis representativas das transferências intergovernamentais manteve-se a inversão constatada no grupo de média renda superior apenas para os municípios de renda dinâmica. Os coeficientes do FPM e cota parte do ICMS mantiveram seus efeitos positivos no resultado orçamentário, porém, com coeficientes maiores para o FPM no grupo dinâmico e cota parte do ICMS no grupo estagnado. Tendo em vista tal resultado, é importante destacar que, uma vez que o grupo média renda inferior estagnada registrou o menor $\mathrm{R}^{2}$ dentre os modelos analisados, existe a possibilidade de considerar a complementação de alguma variável importante para a explicação do resultado orçamentário dessa classificação de municípios.

Tabela 5 - Resultados do painel de dados para os modelos de média renda inferior dinâmica e estagnada

\begin{tabular}{c|ccc|ccc}
\hline \multirow{2}{*}{ Variável } & \multicolumn{3}{|c|}{ Modelo 4 } & \multicolumn{3}{c}{ Modelo 5 } \\
\cline { 2 - 7 } & Coeficiente & p-valor & & Coeficiente & p-valor & \\
\hline Const & $-20117,6$ & 0,60809 & & -219982 & $<0,00001$ & $* * *$ \\
Rec_Trib & 0,276479 & $<0,00001$ & $* * *$ & 0,0983825 & $<0,00001$ & $* * *$ \\
Cota_ICMS & 0,163167 & $<0,00001$ & $* * *$ & 0,134312 & $<0,00001$ & $* * *$ \\
Cota_FPM & 0,204929 & $<0,00001$ & $* * *$ & 0,119772 & $<0,00001$ & $* * *$ \\
Out_Rec_Cor & 0,599654 & $<0,00001$ & $* * *$ & 0,460282 & $<0,00001$ & $* * *$ \\
Rec_Cap & 0,437496 & $<0,00001$ & $* * *$ & 0,36712 & $<0,00001$ & $* * *$ \\
Desp_Pes & $-0,0786658$ & $<0,00001$ & $* * *$ & $-0,0211098$ & 0,00007 & $* * *$ \\
Out_Desp_C & $-0,157726$ & $<0,00001$ & $* * *$ & $-0,0550568$ & $<0,00001$ & $* * *$ \\
Desp_Cap_ & $-0,359293$ & $<0,00001$ & $* * *$ & $-0,27524$ & $<0,00001$ & $* * *$ \\
Ajust & $-0,281241$ & 0,00015 & $* * *$ & $-0,3307$ & $<0,00001$ & $* * *$ \\
Amort_Div & $-0,280$, & & & & & \\
Restos_Pagar & $-0,169312$ & $<0,00001$ & $* * *$ & $-0,178647$ & $<0,00001$ & $* * *$ \\
R-quadrado & 0,44577 & & & 0,25263 & & \\
\hline
\end{tabular}

Fonte: Elaboração própria.

Nos modelos de baixa renda dinâmica e estagnada (Tabela 6), também se registraram todas as variáveis, sem exceção, com significância para explicar o resultado orçamentário dos municípios. A capacidade preditiva dos modelos de baixa renda dinâmica e baixa renda estagnada foram, respectivamente, $27 \%$ e 37\%.

As receitas tributárias se mostraram mais relevantes para o resultado orçamentário nos municípios de baixa renda estagnados. As variáveis receitas de ca- 
pital e outras receitas correntes apresentaram os coeficientes positivos mais elevados. Já as despesas de capital ajustadas foram as variáveis com o maior coeficiente negativo dentro dos grupos de baixa renda. A variável de amortização da dívida registrou coeficiente negativo elevado para o grupo de baixa renda estagnada, entretanto, no grupo baixa renda dinâmica seu valor se apresentou positivo. Neste ponto também cabe destacar a significância estatística ao nível de $5 \%$ e a consideração de outras variáveis para aumentar a capacidade de predição do modelo.

Para as transferências intergovernamentais ambos os grupos registraram o coeficiente do FPM maior do que o coeficiente da cota parte do ICMS. Contudo, nota-se que para os municípios de baixa renda estagnada o coeficiente de repasses da União mostrou-se substancialmente maior, 0,30 ante 0,13 . Tal constatação corrobora com Ter-Minassian (2012), uma vez que demonstra o uso das transferências intergovernamentais com o objetivo de redistribuição regional de recursos, por conseguinte, os resultados confirmam a relevância da renda institucional no orçamento de tais municípios.

Tabela 6 - Resultados do painel de dados para os modelos de baixa renda dinâmica e estagnada

\begin{tabular}{c|ccc|ccc}
\hline \multirow{2}{*}{ Variável } & \multicolumn{3}{|c|}{ Modelo 6 } & \multicolumn{3}{c}{ Modelo 7 } \\
\cline { 2 - 7 } & Coeficiente & p-valor & & Coeficiente & p-valor \\
\hline Const & -289644 & $<0,00001$ & $* * *$ & -438327 & $<0,00001$ & $* * *$ \\
Rec_Trib & 0,178795 & 0,00002 & $* * *$ & 0,413807 & $<0,00001$ & $* * *$ \\
Cota_ICMS & 0,139813 & $<0,00001$ & $* * *$ & 0,130293 & $<0,00001$ & $* * *$ \\
Cota_FPM & 0,162789 & $<0,00001$ & $* * *$ & 0,307032 & $<0,00001$ & $* * *$ \\
Out_Rec_Cor & 0,320828 & 0,00009 & $* * *$ & 0,34721 & $<0,00001$ & $* * *$ \\
Rec_Cap & 0,363479 & $<0,00001$ & $* * *$ & 0,433288 & $<0,00001$ & $* * *$ \\
Desp_Pes & $-0,022647$ & 0,00352 & $* * *$ & $-0,0474956$ & $<0,00001$ & $* * *$ \\
Out_Desp_C & $-0,121717$ & $<0,00001$ & $* * *$ & $-0,218011$ & $<0,00001$ & $* * *$ \\
Desp_Cap_Ajust & $-0,2878$ & $<0,00001$ & $* * *$ & $-0,32311$ & $<0,00001$ & $* * *$ \\
Amort_Div & 0,155904 & 0,03111 & $* *$ & $-0,303763$ & $<0,00001$ & $* * *$ \\
Restos_Pagar & $-0,105595$ & $<0,00001$ & $* * *$ & $-0,137104$ & $<0,00001$ & $* * *$ \\
R-quadrado & 0,273876 & & & 0,373513 & & \\
\hline
\end{tabular}

Fonte: Elaboração própria.

Os Gráficos 1 e 2 sintetizam o comportamento dos coeficientes significativos nos modelos analisados. No Gráfico 1 se tem os coeficientes de receitas e transferências intergovernamentais. Em relação às transferências intergovernamentais os recursos da cota do ICMS tiveram o maior coeficiente (positivo) nos modelos $1 \mathrm{e}$ 
3, categorias de municípios de alta renda $(0,26)$ e média renda superior estagnada $(0,21)$. Já os recursos da cota do FPM foram maiores e positivos, respectivamente, nos modelos de baixa renda estagnada $(0,3)$ e média renda superior estagnada $(0,27)$.

Gráfico 1 - Coeficientes de receitas e transferências nos sete modelos

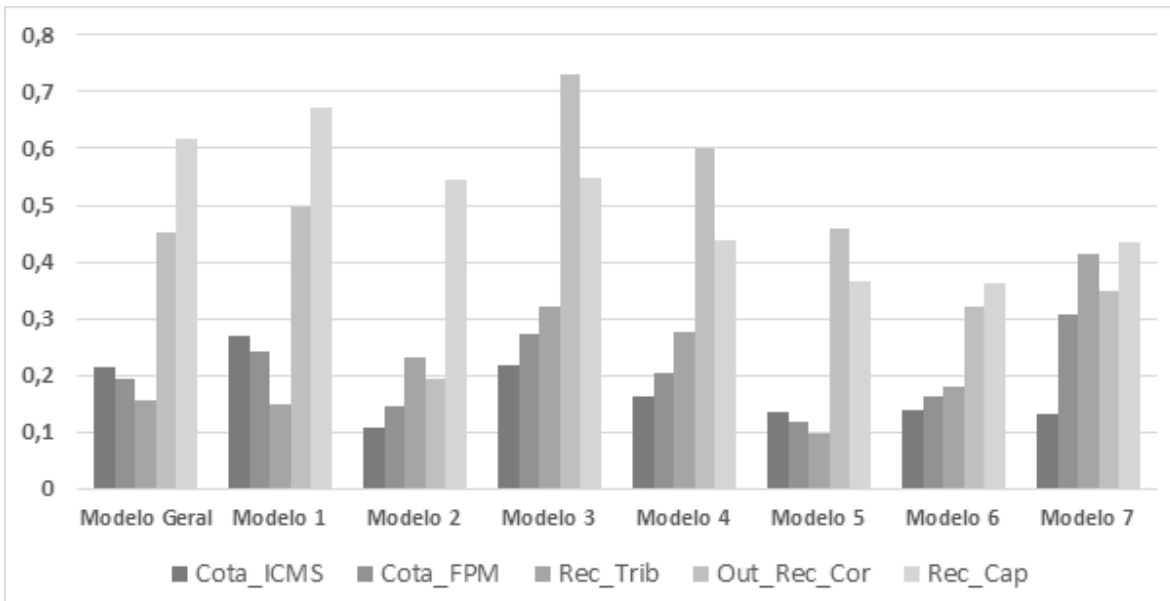

Fonte: Elaboração própria.

Gráfico 2 - Coeficientes de despesas e gastos nos sete modelos

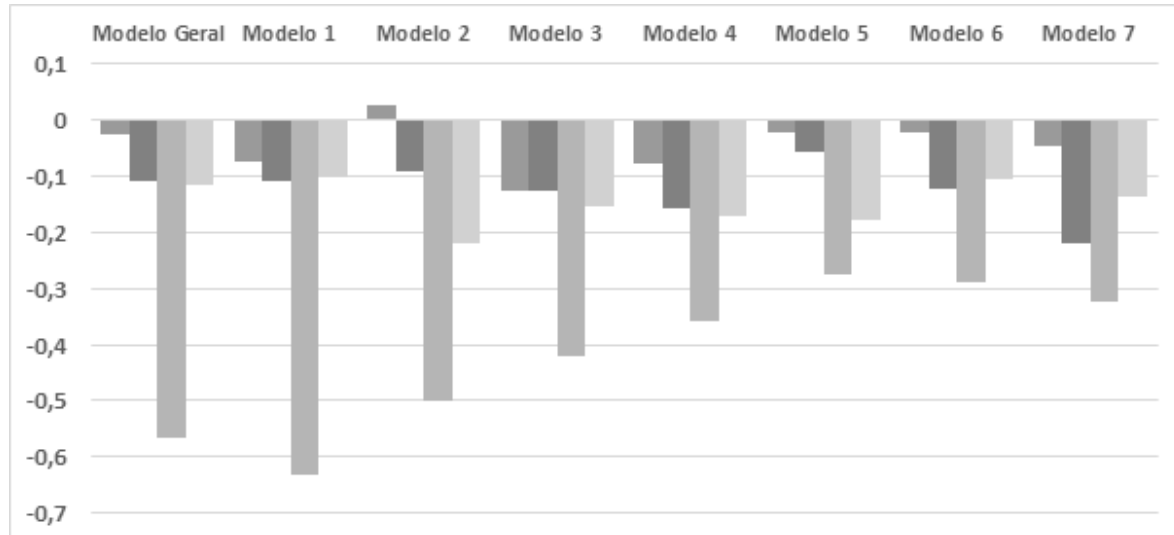

Desp_Pes a Out_Desp_C Desp_Cap_Ajust

Fonte: Elaboração própria.

As receitas tributárias revelaram maiores coeficientes (positivos) nos modelos de baixa renda estagnada $(0,41)$, renda média superior estagnada $(0,32)$ e superior 
dinâmica $(0,27)$. outras receitas correntes registraram maiores coeficientes positivos nos modelos de média renda superior estagnada, inferior dinâmica $(0,59)$, alta renda $(0,49)$ e inferior estagnada $(0,46)$, respectivamente, com destaque para superior estagnada, que registrou coeficiente acima dos 0,7 . já os coeficientes das receitas de capital foram maiores (positivos) nos municípios de alta renda $(0,67)$ e no modelo geral $(0,61)$.

O Gráfico 2 apresenta os coeficientes de despesas e restos a pagar - excluiu-se amortização da dívida por não ter sido significativa em alguns dos modelos. As despesas com pessoal se mostraram com maior efeito negativo para os municípios de média renda superior estagnada $(-0,12)$ e um único efeito positivo para os municípios de renda média superior dinâmica $(0,02)$. Outras despesas correntes registraram maiores coeficiente, também com efeito negativo, nos municípios de baixa renda estagnada $(-0,21)$. Já as despesas de capital ajustadas foram maiores nos modelos com municípios de alta renda $(-0,63)$, geral $(-0,56)$ e média renda superior dinâmica $(-0,5)$. Os coeficientes de restos a pagar foram os que registraram menor variação entre os modelos (entre $-0,1$ e - $-0,2$ ), ligeiramente maior no modelo de renda superior dinâmica $(-0,21)$.

$\mathrm{Na}$ análise comparativa verificou-se que os municípios de média renda superior estagnada apresentaram coeficientes maiores do que a média de todos os outros modelos. Tal diferenciação pode residir no fato de que são microrregiões caracterizadas por terem alcançado certa estabilidade no seu desenvolvimento, porém, enfrentam problemas recentes de dinamismo local (GALVÃO; VASCONCELOS, 1999). Outro ponto de destaque é a relevância das receitas de capital e despesas de capital para o modelo de municípios de alta renda em comparação, principalmente, aos modelos de renda inferior ou baixa renda (dinâmica/estagnada) (BIRD; VAILLANCOURT, 2006).

No caso das transferências intergovernamentais confirmou-se a dependência maior do resultado orçamentário diante das cotas do ICMS e do FPM, modelos de renda estagnada revelaram coeficientes maiores (BIRD; SMART, 2002; SHAH, 1994; TER-MINASSIAN, 1997). Como exceção, cabe destacar que apenas no modelo de renda inferior estagnada tais cotas registraram coeficientes menores, inclusive em comparação a municípios de renda alta e/ou dinâmica. Esse fato representa um alerta sobre as dificuldades que tais municípios podem apresentar e um aparente hiato fiscal (DOWNES; POGUE, 1992; SHAH, 1994; AHMAD; CRAIG, 1997; TER-MINASSIAN, 1997). 


\section{Considerações Finais}

O propósito deste trabalho foi contribuir para uma reflexão parcial acerca dos desequilíbrios da renda institucional e da gestão fiscal entre os entes subnacionais, através da identificação de heterogeneidades fiscais na escala intrarregional, mais especificamente na escala das mesorregiões desagregadas em nível municipal.

Certamente tornou-se claro que um dos principais desafios a serem enfrentados na discussão do federalismo fiscal no Brasil deve ser o das disparidades na renda institucional, uma vez que os mecanismos e políticas federativas, propostas na Constituição Federal de 1988, se mostraram insuficientes para equacionar o "vertical gap" e o "horizontal gap", o que pode explicar parte importante da natureza renitente do nosso subdesenvolvimento.

Os resultados encontrados podem indicar uma possível existência de heterogeneidade entre os grupos, porém, o foco das análises seguiu para a constatação de uma heterogeneidade interna a cada grupo. Assim, destacam-se principalmente tais diferenças nos determinantes do resultado fiscal, que ainda podem nortear duas pesquisas futuras, com questões como: i) heterogeneidade entre grupos pode gerar heterogeneidade interna? e ii) uma variável indicativa do tamanho dos municípios poderia ter poder explicativo?

Ao abranger um período inicial da adoção da política, a PNDR ainda não se converteu numa política de Estado capaz de neutralizar os efeitos negativos das desigualdades regionais e sociais, sobretudo por subestimar as fragilidades fiscais entre os municípios localizados numa mesma escala espacial diferenciada ou no mesmo patamar de desenvolvimento, segundo tipologia bidimensional proposta pela PNDR.

A reflexão em torno da lógica da equidade na federação, a coesão territorial, trata-se de um debate complexo, mas absolutamente necessário, pois a incompatibilidade entre a demanda por bens e serviços públicos e a capacidade fiscal de cada jurisdição implica em restrições à dimensão e à qualidade da provisão desses bens públicos, além de fomentar os conflitos federativos. Diante das considerações lançadas, infere-se que os mecanismos de transferências compensatórias (transferências verticais) são indispensáveis para o enfrentamento das disparidades regionais, para o equilíbrio horizontal e para harmonizar os conflitos federativos. As contribuições da presente pesquisa concernem, sobretudo, a evidenciar os problemas, as desigualdades e as precariedades do sistema fiscal brasileiro e das políticas fiscais municipais, podendo subsidiar uma agenda de propostas ligadas às políticas, como a PNDR, de mudanças legislativas e institucionais na área. 


\section{Referências}

AFFONSO, R. B. A. A crise da federação no Brasil. Ensaios FEE, v. 15, n. 2, p. 321-337, 1994.

AGUIRRE, B. M. B.; MORAES, R. M. Questão federativa no Brasil: "um estado das artes" da teoria. Revista de Economia Política, v. 17, n. 1, p. 121-135, 1997.

AHMAD, E.; CRAIG, J. Intergovernamental transfers. In: TER-MINASSIAN, T. (Ed.). Fiscal federalism in theory and practice. Washington, DC: International Monetary Fund, 1997.

ANDRADE, N. A. Contabilidade pública na gestão municipal. 3. ed. São Paulo: Atlas, 2007.

ARRETCHE, M. et al. Capacidade administrativa, déficit e efetividade da política habitacional. Brasília, DF: Ministério das Cidades, 2007. Disponível em: < http://www.fflch. usp.br/centrodametropole/antigo/v1/mc/assets/pdfs/capacidades_web.pdf > . Acesso em: 19 dez. 2016.

AZEVEDO, R. R. Uma análise dos índices da Lei de Responsabilidade Fiscal nos municípios paulistas após a implantação do projeto AUDESP. Revista de Gestão, Finanças e Contabilidade, v. 3, n. 2, p. 36-60, 2013.

AZZONI, C. R. Indústria e reversão da polarização no Brasil. São Paulo: IPE-USP, 1986.

BACELAR, T. A "questão regional" e a "questão nordestina". In: TAVARES, M. C. (Org.). Celso Furtado e o Brasil. São Paulo: Editora Fundação Perseu Abramo, 2000. p. 71-92.

BALTAGI, B. H. Econometric analysis of panel data. 3. ed. New York: Wiley, 2005.

BANCO NACIONAL DE DESENVOLVIMENTO ECONÔMICO E SOCIAL. Critério de classificação de microrregiões: PDR. 2016. Disponível em: <http://www.bndes.gov.br/ SiteBNDES/export/sites/default/bndes_pt/Galerias/Arquivos/produtos/download/PDR criterio_classificacao.pdf $>$. Acesso em: 06 maio 2013.

BIRD, R. M.; SMART, M. Intergovernmental fiscal transfers: International lessons for developing countries. World Development, v. 30, n. 6, p. 899-912, 2002.

BIRD, R. M.; VAILLANCOURT, F. (Ed.). Perspectives on fiscal federalism. Washington, DC: World Bank Publications, 2006.

BRANDÃO. C. A. O processo de subdesenvolvimento, as desigualdades espaciais e o "jogo das escalas". Pará: UFPA, 2004. (Working paper, n. 39).

BRASIL. Ministério da Integração Nacional. I Conferência de Desenvolvimento Regional (I CNDR): texto de referência (Resumo Executivo). Brasília, DF, 2012.

Ministério da Integração Nacional. Política nacional de desenvolvimento regional: uma proposta para discussão. Brasília, DF, 2003.

BUCHANAN, J. M.; TULLOCK, G. The calculus of consent. Ann Arbor: University of Michigan Press, 1962. 
CANO, W. Concentração e desconcentração econômica regional no Brasil: 1970/95. Economia e Sociedade, v. 6, n. 1, p. 101-141, jun. 1997.

. Desconcentração produtiva regional no Brasil. São Paulo: Editora Unesp, 2008.

. Desequilíbrios regionais e concentração industrial no Brasil: 1930-1970. 3. ed. São Paulo: Editora Unesp, 2007.

. Novas determinações sobre as questões regional e urbana após 1980. São Paulo: Unicamp, jul. 2011. (Texto para discussão, n. 193).

CARVALHO, F. F. Sudene: do desenvolvimento cepalino ao desenvolvimento endógeno. In: SEMINÁRIO INTERNACIONAL TRAJETÓRIAS DE DESENVOLVIMENTO LOCAL E REGIONAL: UMA COMPARAÇÃO ENTRE AS REGIÕES DO NORDESTE BRASILEIRO E A BAIXA CALIFÓRNIA, MÉXICO. 2008. Fortaleza. Anais... Fortaleza: RIC-Colef, 2008.

CAVALCANTI, A. Regime federativo e república Brasileira. Rio de Janeiro: Imprensa Nacional, 1900.

DALLARI, D. A. O Estado Federal. São Paulo: Ática, 1986.

DINIZ, C. C. Desenvolvimento poligonal no Brasil: nem desconcentração, nem contínua polarização. Nova Economia, v. 3, n. 1, p. 35-64, 1993.

DOWNES, C.; POGUE, V. Intergovernamental aid to reduce disparities: problems of definition and mesurement. Public Finance Quarterly, v. 20, n. 4, p.468-482, 1992.

FURTADO, C. O nordeste e a saga da Sudene (1958-1964). Rio de Janeiro: Contraponto; Centro Internacional Celso Furtado de Políticas para o Desenvolvimento, 2009.

GALVÃO, A. C. F.; VASCONCELOS, R. R. Política regional à escala sub-regional: uma tipologia territorial como base para um Fundo de Apoio ao Desenvolvimento Regional. Rio de Janeiro: Ipea, ago. 1999. (Texto para discussão, n. 665).

GREEN, W. H. Econometric analysis. 5. ed. New Jersey: Prentice Hall, 2002.

GUIMARÃES NETO, L. Desigualdades e políticas regionais no Brasil: caminhos e descaminhos. Planejamento e Políticas Públicas - IPEA, n. 15, p. 41-95, 1997b.

. Introdução à formação econômica do Nordeste. Recife: Massangana; Fundação Joaquim Nabuco, 1989.

Nordeste: da articulação comercial à integração produtiva. 1986. 362 f. Tese (Doutorado em Economia) - Instituto de Economia Universidade Estadual de Campinas, Campinas, 1986.

. Trajetória econômica de uma região periférica. Estudos Avançados, v. 11, n. 29, p. 37-54, 1997a.

GUJARATI, D. N.; PORTER, D. C. Econometria básica. 5. ed. Porto Alegre: McGraw-Hill Bookman, 2011. 
IBGE. Divisão do Brasil em mesorregiões e microrregiões geográficas. Rio de Janeiro: Fundação do Instituto Brasileiro de Geografia e Estatística (FIBGE), 1990. Disponível em: $<$ http://biblioteca.ibge.gov.br/visualizacao/monografias/GEBIS\%20-\%20RJ/DRB/Divisao\%20 regional_v01.pdf>. Acesso em: 20 dez. 2016.

INMAN, R. P. The flypaper effect. Cambridge: National Bureau of Economic Research, 2008. (NBER Working paper, n. 14579). Availble in: <http://www.nber.org/papers/w14579>. Acess in: 19 Dec. 2016.

LOPREATO, F. L.; PAIVA, C. C. Evolução das finanças públicas da Região Metropolitana de Campinas: tendências e perspectivas. In: CANO, W.; BRANDÃO, A. C. A região Metropolitana de Campinas: urbanização, economia, finanças e meio ambiente. Campinas: Unicamp, 2002. v. 2.

MACEDO, J. J.; CORBARI, E. C. Efeitos da Lei de Responsabilidade Fiscal no endividamento dos municípios brasileiros: uma análise de dados em painéis. Revista Contabilidade $\mathcal{E}$ Finanças, São Paulo, v. 20, n. 51, p. 44-60, 2009.

MATIAS, A. B.; CAMPELLO, C. A. G. B. Administração financeira municipal. São Paulo: Atlas, 2000 .

MENDES, M. Capture of fiscal transfers: a study of Brazilian local governments. Economia aplicada, v. 9, n. 3, p. 427-444, 2005.

. Federalismo Fiscal. In: ARVATE, P. R.; BIDERMAN, C. Economia do setor público no Brasil. Elsevier: Rio de Janeiro, 2004. p. 421-461

MONTEIRO NETO, A. Desenvolvimento regional em crise: políticas econômicas liberais e restrições à intervenção estatal no Brasil dos anos 90. 2005. 299 f. Tese (Doutorado em Economia) - Instituto de Economia, Universidade Estadual de Campinas, Campinas. 2005.

OLIVEIRA, F. A questão regional: a hegemonia inacabada. Estudos avançados, v. 7, n. 18, p. 43-63, 1993.

PACHECO, C. A. A fragmentação da nação. Campinas: Unicamp, 1998.

. A questão regional brasileira pós 1980: desconcentração econômica e fragmentação da economia nacional. 1996a. 334 f. Tese (Doutorado em Economia)-Instituto de Economia Universidade Estadual de Campinas, Campinas, 1996a.

. Desconcentração econômica e fragmentação da economia nacional. Economia e Sociedade, n. 6, p. 113-140, junho 1996b.

SANTOLIN, R.; JAIME JUNIOR, F. G.; REIS, J. C. Lei de Responsabilidade Fiscal e implicações na despesa de pessoal e de investimento nos municípios mineiros: um estudo com dados em painel dinâmico. Estudos Econômicos, v. 39, n. 4, p. 895-923, 2009.

SHAH, A. A fiscal needs approach to equalization transfers in a decentralized federation. Washington, DC: World Bank, 1994. (Policy Research Working papers, n. 1289).

TER-MINASSIAN, T. Intergovernamental fiscal relations. In: TER-MINASSIAN, T. Fiscal federalism in theory and practice. (Ed.). Washington D.C.: International Monetary Fund, 1997. 
TER-MINASSIAN, T. Reforma do fundo de participação dos Estados (FPE). Washington, DC: Inter-American Development Bank, 2012. (Working paper, n. IDB-DP-216).

TORRES, J. C. O. A formação do federalismo no Brasil. São Paulo: Companhia Editora Nacional, 1961.

WOOLDRIDGE, J. M. Econometric analysis of cross section and panel data. $2^{\text {nd }}$. ed. Boston: The MIT Press, 2010.

ZUCCOLOTTO, R.; RIBEIRO, C. P. P.; ABRANTES, L. A. O comportamento das finanças públicas municipais nas capitais dos estados brasileiros. Revista Enfoque Reflexão Contábil, v. 28 , n. 1, p. 54-69, 2009.

Recebido em: 18/12/2014.

Aceito em: 23/01/2017. 